\title{
Digestibilidade Verdadeira da Lisina HCl e da Lisina Sulfato Determinada com Galos Cecectomizados ${ }^{1}$
}

\author{
Rafael Neme ${ }^{2}$, Luiz Fernando Teixeira Albino ${ }^{3}$, Horacio Santiago Rostagno ${ }^{3}$, \\ Ramalho José Barbosa Rodrigueiro ${ }^{4}$, Ricardo Vianna Nunes ${ }^{4}$
}

RESUMO - O objetivo deste trabalho foi determinar a digestibilidade verdadeira da lisina $\mathrm{HCl}$ e da lisina Sulfato, com galos adultos cecectomizados. Foram utilizados 18 galos Leghorn, cecectomizados, com peso médio de 2,854 kg, e alojados individualmente em gaiolas metálicas durante dez dias. Após os dois primeiros dias de adaptação às baterias, estes animais passaram por um período de cinco dias recebendo ração em dois períodos diários de uma hora cada (manhã, 8 h e tarde, 16 h), com o objetivo de dilatação do papo para evitar regurgitação da ração a ser introduzida. Foi utilizado o método de alimentação forçada, com 12 galos alojados individualmente em gaiolas metálicas com bandejas coletoras de excretas. O delineamento experimental foi inteiramente casualisado com dois tratamentos (duas fontes de lisina), com seis repetições cada. Um ensaio paralelo com 6 aves em jejum foi conduzido para determinação das perdas endógenas/ metabólicas das aves. Os teores de aminoácidos das dietas e das excretas foram analisados para a determinação dos coeficientes de digestibilidade verdadeira das lisinas. Os coeficientes de digestibilidade verdadeira, expressos em porcentagem, foram de $97,59 \%$ para a lisina $\mathrm{HCl}$ e de $98,34 \%$ para a lisina sulfato, não diferindo estatisticamente.

Palavras-chave: digestibilidade verdadeira, lisina, galos cecectomizados, alimentação forçada

\section{True Digestibility of Lysine HCl and Lysine Sulfate Determinated with Cecectomized Adult Roosters}

\begin{abstract}
The objective of this experiment was to determine the true digestibility of lysine $\mathrm{HCl}$ and lysine sulfate, with cecectomized adult roosters. Eighteen roosters, $2.854 \mathrm{~kg}$ live weight, were cecectomized and kept in cages for a period of 10 days. After two days of adaptation to the cages the animals were fed twice a day during one hour (8:00 a.m. to 9:00 am and 4:00 p.m. to 5:00 pm), for crop dilation to avoid regurgitation of the feed. The forced fed method was utilized, with 12 roosters placed in individual cages equipped with excreta collection pans. The experiment design was complete randomized, with two treatments (two lysine sources) each one with six replicates. Also six birds were fasted to determine the endogenous/metabolic loses. Diets and excreta were analyzed to determine amino acid contents and the true lysine digestibility coefficients calculatted. The true digestibility coefficients, in percentage, were $97.59 \%$ for lysine $\mathrm{HCl}$ and $98.34 \%$ for lysine sulfate, they were not statistically different.
\end{abstract}

Key Words: cecectomized roosters, forced fed, lysine, true digestibility

\section{Introdução}

Diferentes metodologias de produção de aminoácidos sintéticos estão sendo desenvolvidas com a finalidade de se elaborar produtos para o mercado de rações que propiciem melhorias no desempenho animal e diminuição no custo de produção.

Várias pesquisas estão sendo desenvolvidas com o objetivo de testar a digestibilidade de nutrientes obtidos por diferentes processos. A disputa entre as diferentes empresas pelo concorrido mercado de rações, no caso em questão os aminoácidos, gera uma situação em que se podem esperar produtos de melhor qualidade e menor custo.
Com a precisa integração das informações sobre as aves, os alimentos e o ambiente, tornou-se possível fazer simulações com modelos matemáticos, com o intuito de predizer o consumo adequado de um nutriente, a taxa de crescimento subseqüente, para um dado animal, em determinado estado metabólico e ambiente.

Os gastos com alimentação na avicultura correspondem aproximadamente a $70 \%$ do custo de produção do frango de corte, sendo os alimentos protéicos os mais onerosos. Por conseqüência, a utilização de aminoácidos sintéticos, segundo AUSTIC (1985), possibilita reduzir o custo de produção das rações, com a redução do nível de proteína. Também por serem mais disponíveis diminuem a poluição

\footnotetext{
${ }_{1}^{1}$ Parte da tese de Mestrado do primeiro autor.

2 Estudante de Doutorado FACV - UNESP/Jaboticabal. E.mail: neme@fcav.unesp.br

3 Professor Titular DZO/UFV. E.mail: lalbino@mail.ufv.br; rostagno@mail.ufv.br

${ }^{4}$ Estudante de Doutorado DZO/UFV.
} 
ambiental através da diminuição na quantidade de nitrogênio excretado pelas aves (PENZ JR., 1990). No entanto, segundo EMMERT et al. (1999), a diminuição dos preços dos aminoácidos sintéticos nos últimos anos é que contribuiu para a adoção de dietas com menores níveis de proteína bruta.

Vários trabalhos foram desenvolvidos com o intuito de se substituir parte da proteína bruta da dieta por aminoácidos sintéticos. Entretanto há um questionamento, por alguns autores, sobre a eficiência de suplementação de aminoácidos.

Parece existir, segundo PENZ JR. (1990), um limite para a substituição da proteína intacta por aminoácidos sintéticos, sendo que o problema de uma maior velocidade de absorção destes aminoácidos, resultariam em um descompasso entre a quantidade disponível para a síntese e a velocidade da mesma.

HAN et al. (1992) demonstraram que aves recebendo dietas com baixo teor protéico (19\%), suplementadas com aminoácidos sintéticos, apresentaram desempenhos semelhantes quanto ao ganho de peso, eficiência alimentar e gordura corporal, quando comparadas às aves que receberam dietas contendo $23 \%$ de proteína bruta. Isto pode representar significativo ganho econômico, com a redução do custo da ração.

Diversos autores avaliaram rações suplementadas com aminoácidos, com o objetivo de evitar o uso ineficiente do excesso de aminoácidos como fonte de energia, o que seria extremamente oneroso, determinando assim os níveis ideais de cada aminoácido nas rações para cada fase do crescimento animal.

Alguns estudos utilizam os termos digestibilidade e disponibilidade dos nutrientes erroneamente como sinônimos. Nos animais, a digestibilidade e a disponibilidade definem o valor potencial da proteína dos alimentos (FULLER e WANG 1990). A digestibilidade deve ser entendida como a medida do desaparecimento de um nutriente durante sua passagem pelo trato digestivo e não como sua absorção, uma vez que este nutriente pode ser destruído ou modificado pela ação dos microrganismos em alguns locais do trato digestivo ou metabolizado pelas paredes do mesmo durante a absorção (RÉRAT, 1990). Por outro lado, a disponibilidade deve ser definida como a proporção daquele aminoácido da dieta que foi digerido, absorvido e utilizado para a síntese de proteína (BATTERHAM 1992).

Vários pesquisadores utilizam os valores de digestibilidade e disponibilidade dos aminoácidos para formular rações de alta qualidade para produção de carne e ovos, atendendo-se assim mais a mistura de aminoácidos do que do teor de proteína bruta de rações (COON 1991).

A digestibilidade aparente é obtida ao calcular-se os valores de aminoácidos das excretas, ou em material coletado do íleo terminal, e subtraído os valores dos níveis de aminoácidos consumidos. A digestibilidade verdadeira é, então, determinada com os valores de aminoácidos endógenos encontrados na excreta de animais alimentados com uma dieta isenta de proteína ou em jejum.

A determinação da digestibilidade dos aminoácidos pode ser feita por intermédio do método de coleta total de fezes e de indicador fecal, sendo o mais utilizado o óxido crômico. Este último método apresentou valores de digestibilidade, aproximadamente, $10 \%$ menores que os encontrados pelo método de coleta fecal total sem o uso de indicadores, ROSTAGNO e FEATHERSON (1977).

O método de alimentação forçada desenvolvido por SIBBALD (1978), utilizando-se de aves normais ou cecectomizadas, para determinação de energia metabolizável verdadeira, pode ser utilizado para determinação da digestibilidade verdadeira de aminoácidos.

Segundo BELLAVER (1994), esta técnica de alimentação precisa com galos, para determinação da energia metabolizável dos ingredientes, foi posteriormente adaptada por LIKUSKI e DORRELL (1978) para a determinação do coeficiente de digestibilidade dos aminoácidos. Dessa forma, esta metodologia é largamente utilizada para a determinação de tais coeficientes nos alimentos e ingredientes utilizados nas rações na avicultura industrial.

A utilização de galos cecectomizados tem sido proposta uma vez que o ceco é o maior local de atividade microbiana do trato gastrointestinal, sendo estes capazes de sintetizar aminoácidos ou utiliza-los sem benefício para as aves, prejudicando então a avaliação da digestibilidade. A cecectomia, extirpação dos cecos através de cirurgia, é necessária para reduzir a alta degradação microbiana dos aminoácidos na porção final do trato gastrointestinal PARSONS et al. (1981).

Segundo JOHNS et al. (1986 a, b), cerca de 20 a $25 \%$ dos aminoácidos eliminados na excreta das aves são de origem microbiana, sendo que os galos cecectomizados produzem maior quantidade de aminoácidos endógenos na excreta que galos normais.

O período de jejum praticado para esvaziamento completo do trato digestivo dos galos é considerado por alguns autores responsável por possível mudança na digestão dos alimentos fornecidos após este período. 
KEULDER (1995), testando diferentes períodos de jejum $(4,8,12,16$ horas), não encontrou efeito dos tratamentos na digestibilidade verdadeira da lisina com aves. Da mesma forma, KADIM e MOUGHAN (1997) não encontraram efeito significativo na digestibilidade ileal aparente do nitrogênio, com frangos de corte machos e fêmeas, submetidos anteriormente a dois períodos de jejum (12 e 24 horas). Foi observado, porém, que a variação dos dados de digestibilidade entre as repetições foram bem menores para as aves submetidas ao período de 24 horas de jejum.

Segundo ALBINO (1991), a digestibilidade dos aminoácidos varia de acordo com o alimento e, certas vezes, até mesmo dentro de amostras diferentes de um mesmo alimento ou processamento a que estes são submetidos. No entanto, há algumas interações animal/alimento que não podem ser ignoradas, pois influem na disponibilidade dos nutrientes.

IZQUIERDO et al. (1988) encontraram em experimentos com galos sob alimentação precisa valores de digestibilidade verdadeira para L-lisina $\mathrm{HCl}$ de 98,40 e $97,00 \%$, para correção com aves em jejum e com caseína, respectivamente. Os coeficientes de digestibilidade verdadeira para lisina $\mathrm{HCl}$, encontrados por CHUNG e BAKER. (1992) e SIBBALD e WOLYNETZ (1985), foram, respectivamente, 95,60 e 92,00\%.

Assim, este trabalho teve como objetivo determinar a digestibilidade verdadeira de duas fontes de lisina (Lisina $\mathrm{HCl}$ com 79,0\% de L-lisina e Lisina Sulfato com $46,8 \%$ de L-lisina).

\section{Material e Métodos}

Foram utilizados 18 galos Leghorn adultos, cecectomizados segundo a técnica modificada proposta por PUPA et al. (1998), com peso médio de $2,854 \mathrm{~kg}$, alojados individualmente em gaiolas metálicas durante dez dias. Após os dois primeiros dias de adaptação às baterias, estes animais passaram por um período de cinco dias recebendo ração em dois períodos diários de uma hora cada (manhã, $8 \mathrm{~h}$ e tarde, $16 \mathrm{~h}$ ), com o objetivo de dilatação do papo para evitar regurgitação da ração a ser introduzida. O programa de iluminação foi de acordo com o fotoperíodo local, resultando em um período médio diário de 12 horas.

Foiutilizadodelineamento experimental inteiramente casualizado com dois tratamentos (duas fontes de lisina) e um ensaio com aves em jejum, com seis repetições cada e uma ave (galo) por unidade experimental.
Para determinação da digestibilidade verdadeira dos aminoácidos, foram formuladas dietas experimentais purificadas (Tabela 1).

Tabela 1 - Composição percentual das dietas purificadas Table 1 - Percentage composition of purified diets

\begin{tabular}{|c|c|c|}
\hline \multirow[t]{2}{*}{$\begin{array}{l}\text { Ingredientes } \\
\text { Ingredients }\end{array}$} & \multicolumn{2}{|c|}{$\begin{array}{c}\text { Composição }{ }^{\mathrm{a}}(\%) \\
\text { Composition }\end{array}$} \\
\hline & $\begin{array}{l}\text { Tratamento } 1 \\
\text { Treatment }\end{array}$ & $\begin{array}{c}\text { Tratamento } 2 \\
\text { Treatment }\end{array}$ \\
\hline Amido de milho & 69,56 & 68,94 \\
\hline Corn starch & & \\
\hline $\begin{array}{l}\text { Mistura de aminoácidos } \\
\text { Amino acids pool }\end{array}$ & 13,69 & 13,69 \\
\hline $\begin{array}{l}\text { Lisina } \mathrm{HCl} 79 \% \\
\text { Lysine } \mathrm{HCl}\end{array}$ & 1,330 & - \\
\hline $\begin{array}{l}\text { Lisina sulfato } 46,8 \% \\
\text { Lysine sulfate }\end{array}$ & - & 2,24 \\
\hline $\begin{array}{l}\text { Caulim } \\
\text { Caulim }\end{array}$ & 4,18 & 3,89 \\
\hline $\begin{array}{l}\text { Óleo de soja } \\
\text { Soybean oil }\end{array}$ & 4,00 & 4,00 \\
\hline $\begin{array}{l}\text { Casca de arroz } \\
\text { Rice seed coat }\end{array}$ & 3,00 & 3,00 \\
\hline $\begin{array}{l}\text { Bicarbonato de sódio } \\
\text { Sodium bicarbonate }\end{array}$ & 1,00 & 1,00 \\
\hline $\begin{array}{l}\text { Pré-mistura } \\
\text { Mineral and vitamin }\end{array}$ & 0,19 & 0,19 \\
\hline $\begin{array}{l}\text { Sal } \\
\text { Salt }\end{array}$ & 0,30 & 0,30 \\
\hline $\begin{array}{l}\text { Calcário } \\
\text { Limestone }\end{array}$ & 1,10 & 1,10 \\
\hline $\begin{array}{l}\text { Fosfato bicálcico } \\
\text { Dicalcium phosphate }\end{array}$ & 1,65 & 1,65 \\
\hline $\begin{array}{l}\text { Total } \\
\text { Valores analisados } \\
\text { Analyzed composition }\end{array}$ & 100,00 & 100,00 \\
\hline $\begin{array}{l}\text { Proteína bruta \% } \\
\text { Crude protein }\end{array}$ & 11,14 & 11,35 \\
\hline $\begin{array}{l}\text { Lisina } \% \\
\text { Lysine }\end{array}$ & 1,073 & 1,110 \\
\hline
\end{tabular}

a Proteína bruta (Crude protein), 11,10\%; EM (ME), $3402 \mathrm{kcal} / \mathrm{kg}$.

b L-arginina (arginine) 0,44\%; L-histidina (histidine) $\mathrm{HCL} \mathrm{H}_{2} \mathrm{O}, 0,38 \%$; L-tirosina (tirosine) $0,41 \%$; L-fenilalanina (phenylalanine) $0,45 \%$; L-triptofano (tryptophan) 0,14\%; DL-metionina (methionine) $0,32 \%$; L-cistina (cystine) $0,32 \%$; L-treonina (threonine) $0,59 \%$; L-leucina (leucine) 0,90\%; L-isoleucina (isoleucine) 0,59\%; L-valina (valine) $0,62 \%$; L - prolina (proline) $0,30 \%$; glicina (gyicine) $0,90 \%$ e L-glutamato (glutamic acid) $7,33 \%$.

c Níveis de garantia por quilo de ração, $\mathrm{Fe}-0,048 \mathrm{~g} ; \mathrm{Cu}-0,006 \mathrm{~g}$; Co - 0,0012 g; Mg - 0,036 g; Zn - 0,03 g; I - 0,0006 g;Vit. A 18.000 UI; Vit. $D_{3}-1800$ UI; Vit. E - 18 U.I.; Vit. $B_{1}-2,4$ mg; Vit. $B_{2}$ - 4,8 mg; Vit. $B_{6}-3,6 \mathrm{mg}$; Vit. $\mathrm{B}_{12}-0,018 \mathrm{mg}$; ácido nicotínico (nicotinic acid) - $30 \mathrm{mg}$; ácido pantotênico (pantotenic acid) $12 \mathrm{mg}$; Vit. $\mathrm{K}_{3}$ - 3,6 mg; ácido fólico (folic acid) - 1,2 mg; colina - $300 \mathrm{mg}$; bacitracina de zinco - $12 \mathrm{mg}$; selênio - 0,3 mg; B.H.T. - $12 \mathrm{mg}$.

d Análises realizadas no laboratório da Degussa (Hulls A G, Feed aditive division). 
Os tratamentos consistiram de duas rações purificadas contendo diferentes fontes de lisina. Paralelamente, seis galos foram mantidos em jejum para determinação das perdas endógenas e metabólicas. TRATAMENTO 1 - Ração purificada contendo lisina $\mathrm{HCl}$

TRATAMENTO 2 - Ração purificada contendo lisina sulfato

O período experimental total foi de 80 horas, nas primeiras 24 horas os animais ficaram em jejum para ocorrer o esvaziamento completo do aparelho digestivo. Após este período os 12 animais referentes aos tratamentos 1 e 2 foram alimentados com 30 gramas de ração do respectivo tratamento ( $15 \mathrm{~g}$ às $8 \mathrm{~h}$ e $15 \mathrm{~g}$ às $16 \mathrm{~h}$ ), por intermédio de um funil-sonda introduzido via oral até o papo. Durante todo período experimental, foi fornecida água à vontade. Paralelamente, foram alojadas nas mesmas condições seis galos em jejum por um período de 56 horas, para realização das correções correspondentes as excreções basais e endógenas/metabólicas.

A coleta total de excretas foi realizada nas 48 horas após os animais receberem a segunda alimentação forçada, ocorrendo duas vezes a cada 24 horas. Para possibilitar as coletas, bandejas foram revestidas com plástico e acondicionadas sob o piso das gaiolas de cada galo.

Todo o material recolhido (excreta) foi armazenado em frascos de vidro com tampa e colocados em um congelador. Ao término do período de coleta, as amostras de cada repetição foram descongeladas, pesadas, homogeneizadas e liofilizadas. Para determinar o conteúdo aminoacídico, as amostras de excretas bem como das rações, foram enviadas para o laboratório de análises químicas da Empresa Degussa - Hulls A G, Feed aditive division.

Entre as formas de aminoácidos sintéticos testadas neste trabalho estão a lisina sulfato, que contém um mínimo de 46,8\% de L-lisina na forma de sais de sulfato, umidade máxima de $5 \%$, densidade de $680 \mathrm{~kg} / \mathrm{m}^{3}$ $\pm 10 \%, 75 \%$ de proteína bruta, $3740 \mathrm{kcal} / \mathrm{kg} \mathrm{e} 0,2 \%$ de fósforo (Degussa 1998), e a lisina $\mathrm{HCl}$, que contém um mínimo de 79,0\% de L-lisina, umidade máxima de 1,50 e $99 \%$ de pureza (Ajinomoto).

As análises estatísticas das características estudadas foram realizadas de acordo com o programa SAEG (Sistemas de Análises Estatísticas e Genéticas) UFV, versão 8.0 (2000).

\section{Resultados e Discussão}

Os coeficientes de digestibilidade, obtidos para as duas fontes de lisina, utilizando galos cecectomizados, estão apresentados na Tabela 2.

Como mostrado no quadro acima, a excreção de lisina endógena, determinada com galos em jejum durante o período experimental foi de $30,47 \mathrm{mg}$. O consumo de lisina por ave alimentada com a dieta purificada contendo Lisina $\mathrm{HCl}$ foi de $321,9 \mathrm{mg}$, seguida de uma excreção de $38,22 \mathrm{mg}$. Ao considerar a excreção de lisina das aves em jejum, obtém-se o coeficiente de digestibilidade verdadeira para a lisina $\mathrm{HCl}$, onde a média das três repetições foi de $97,59 \%$.

Quanto àlisina sulfato, o consumo por ave foi de 333,0 $\mathrm{mg}$, sendo detectado nas excretas uma quantidade de 5,53 $\mathrm{mg}$ de lisina a mais do que a quantidade excretada pelos galos em jejum, resultando em um coeficiente de digestibilidade verdadeira de $98,34 \%$. Dessa forma, verificou-se não haver diferença $(\mathrm{P}=0,05)$ entre os coeficientes de digestibilidade verdadeira das duas fontes de lisina. O resultado obtido neste experimento, para a fonte de lisina $\mathrm{HCl}$, está próximo dos resultados obtidos por CHUNG e BAKER (1992) com galos cecectomizados, os quais encontraram coeficientes de digestibilidade verdadeira de 95,60\% (correção com galos em jejum) e 97,50\% (correção com galos recebendo dietas com caseína). Valores semelhantes ao encontrado por CHUNG e BAKER (1992) para caseína, foi encontrado

Tabela 2 - Consumo de lisina(CL), excreção de lisina (EL) e coeficientes de digestibilidade verdadeira (CDV) da lisina $\mathrm{HCl}$ e lisina sulfato

Table 2 - Lysine intake (CL), lysine excretion (EL) and true digestibility coefficient (CDV) of lysine sulfate and lysine $\mathrm{HCl}$

\begin{tabular}{lccc}
\hline $\begin{array}{l}\text { Tratamentos } \\
\text { Treatments }\end{array}$ & CL $(\mathrm{mg})$ & EL $(\mathrm{mg})$ & CDV $(\%)$ \\
\hline $\begin{array}{l}\text { Jejum } \\
\text { Fasted }\end{array}$ & - & 30,47 & - \\
$\begin{array}{l}\text { Lisina } \mathrm{HCl} * \\
\text { Lysine }\end{array}$ & 321,9 & 38,22 & $97,59^{\mathrm{a}}$ \\
$\begin{array}{l}\text { Lisina sulfato* } \\
\text { Lysine sulfate }\end{array}$ & 333,0 & 36,00 & $98,34^{\mathrm{a}}$ \\
CV $(\%)$ & & & 1563 \\
\hline
\end{tabular}

Médias nas mesma coluna seguidas de letras iguais não diferem estatisticamente $(P>0,05)$, pelo teste de Newman - Keuls (Means in same column followed of equal letters do not differ by Newman Keuls test).

* Valores médios dos tratamentos (Mean value of the treatments). 
por IZQUIERDO etal.(1988), 97,00\%, que encontraram também para Lisina $\mathrm{HCl}$ um valor muito próximo ao encontrado neste trabalho, $98,40 \%$.

SIBBALD e WOLYNETZ (1985), utilizando a técnica de alimentação precisa com galos cecectomizados, relataram que a digestibilidade da lisina $\mathrm{HCl}$ foi de apenas $92,00 \%$, ou seja, 5,59\% inferior aos dados obtidos neste experimento. No entanto, uma ressalva deve ser feita com os resultados obtidos a partir da metodologia proposta por LIKUSKI e DORRELL (1978), utilizada neste ensaio para determinação de aminoácidos digestíveis, pois o alimento é fornecido aos animais após estes passarem 24 horas em jejum, o que já é necessário para alterar a taxa de passagem dos alimentos, ocasionando a principal fonte de erro deste método (BELLAVER, 1994). Outra questão a ser considerada sobre este método é que, segundo ZHANG et al. (1993), pelo fato de os animais estarem em jejum, os aminoácidos sintéticos são absorvidos pelo trato gastrointestinal mais rapidamente e eficientemente que os aminoácidos provindos de proteínas intactas, o que resultaria em maior concentração de aminoácidos na corrente sangüínea, com subseqüente excreção pela urina.

Em razão de ser uma nova fonte de lisina, recente no mercado, não foi possível encontrar trabalhos de digestibilidade verdadeira com a lisina sulfato. No entanto, ao se comparar a metodologia utilizada neste trabalho com os dados obtidos para a lisina $\mathrm{HCl}$, foi observado que os dados encontrados estão próximos daqueles de outras pesquisas. Pode-se, então, considerar que ambas as fontes de lisina apresentaram valores de digestibilidade verdadeira semelhantes.

\section{Conclusões}

A lisina sulfato e a lisina $\mathrm{HCl}$ apresentam valores semelhantes de coeficiente de digestibilidade verdadeira, 98,34 e 97,59\%, respectivamente. As fontes de lisina estudadas poderão ser utilizadas em rações de frangos de corte, sem comprometer o desempenho e o rendimento de carcaça das aves.

\section{Referências Bibliográficas}

ALBINO, L.F.T. 1991. Sistema de avaliação nutricional de alimentos e suas aplicações na formulação de rações para frangos de corte. Viçosa, MG: UFV, 1991. 141p. Tese (Doutorado em Zootecnia) - Universidade Federal de Viçosa, 1991.

AUSTIC, R.E. 1985. Lysine in poultry nutrition. [S.1]: Ajinomoto. BATTERHAM, E.S. 1992. Availability and utilization of amino acids for growing pigs. Nut. Res. Rev., 5:1-18.

BELLAVER, C. Metodologias para determinação do valor das proteínas e utilização de valores disponíveis nas dietas de não ruminantes. 1994. In: SIMPÓSIO INTERNACIONAL DE
PRODUÇÃO DE NÃO RUMINANTES, 1994, Maringá. Anais... Maringá: SBZ, 1994.

CHUNG, T.K., BAKER, D.H. 1992. Apparent and true amino acid digestibility of a crystalline amino acid mixture and of casein: Comparison of values obtained with ileal-cannulated pigs and cecectomized cockerels. J. Anim. Sci., 70(12):3781-3790.

COON, C.N. Optimizing ingredient utilization through a better understanding of amino acids bioavailability. Proceeding Novus Technical Symposia, p.11-40, México, 1991.

DEGUSSA. Biolys 60. Frankfurt: [1998]. Não paginado. (Folder).

EMMERT, J.L., DOUGLAS, M.W., BOLING, E.D. et al. 1999. Bioavailability of lysine from a liquid lysine source in chicks. Poult Sci. 78(3):383-386.

FULLER, M.F., WANG, T.C. 1990. Digestible ideal protein - a mensure of dietary protein value. Pigs News and Information. 11(3):353-357.

HAN, Y., BAKER, D.H. 1992. Effects of heat stress, sex and body weight on responses of broiler chicks to dietary lysine. Poult. Sci., 71(1):37. Suplement.

IZQUIERDO, O.A., PARSONS, C.M., BAKER, D.H. 1988. Bioavailabiliy oflysineinlysineHCl.J.Anim.Sci.,66(10):2590-2597.

JOHNS, D,C., LOW, C.K., SEDCOLE, J.R. et al. 1986a. Determination of amino acids digestibility using cecectomized and intact adult cockerels. Brit. Poult. Sci., 27:451-461.

JOHNS, D.C., LOW, C.K., JAMES, K.A.C. 1986b. Comparation of amino acids digestibility using the ileal digesta from growing chickens and cannulated adult cockerels. Brit. Poult. Sci., 27:679-685.

KADIN, I.T., MOUGHAN, P.J. 1997. The development of a ileal amino acid digestibility assay for the growing chicken - the effect of time after feeding for sampling digesta and the site of sampling. Brit. Poult. Sci., 38(1):89-95.

KEULDER, H.F. The development of a standardised procedure for the determination of a true digestibility of amino acids in protein sources. In: WORLD'S POULTRY CONGRESS, 16, Scarborough, UK, 1995. Proccedings... Scarborough, 1995. A2:9-18.

LIKUSKI, H.J., DORRELL, H.G. 1978. A bioassay for rapid determinations of amino acid availability values. Poult. Sci., 57(6):1658-1660.

PARSONS, C.M., POTTER, L.M., BROWN JR., R.D. 1981. True metabolizable energy and amino acid digestibility of the hulled soybean meal. Poult. Sci., 60(9):2696-2687.

PENZ JR., A.M. 1990. Exigências de aminoácidos das poedeiras. In: CICLODE CONFERÊNCIAS DA A.V.E. Porto Alegre. Anais... Porto Alegre. 1990. p.88-110.

PUPA, J.M.R., LEÃO, M.I., CARVALHO, A.U., et al. 1998. Cecectomia em galos sob anestesia local e incisão abdominal. Arq. Bras. Med. Vet. Zootec., 50(5):531-535.

RÉRAT, A. 1990. Absorption of nitrogen and amino acids from exogenous (fish meal proteins) or endogenous sources in the pig. Pigs News and Information, 11(2):173-180.

ROSTAGNO, H.S., FEATHERSON, W.R. 1977. Estudo de métodos de determinação de disponibilidade de aminoácidos em pintos. R. Soc. Bras. Zootec. 6(1):64-75.

UNIVERSIDADE FEDERAL DE VIÇOSA - UFV. 1997. SAEG Sistema para Análise Estatística e Genética, versão 7.0. Viçosa: Fundação Arthur Bernardes.

SIBBALD, I.R. 1978. The effect of age of assay bird on the true metabolizable energy values of feedingstuffs. Poult. Sci., 57(4):1008-012.

SIBBALD, I.R., WOLYNETZ, M.S. 1985. The bioavailability of supplementary lysine and its effect on the energy and nitrogen excretion of adult cockerels fed diets diluted with cellulose. Poult. Sci., 64(10):1972-1975.

ZHANG, Y., HERRO, D.R., PARSONS, C. M. 1993. Effect of crystalline lysine and methionine intake on amino acid excretion by precision-fed cockerels. Poult. Sci., 72(6):1180-1183.

Recebido em: 12/01/01 Aceito em: 27/05/01 